\title{
PERANCANGAN DAN IMPLEMENTASI SISTEM MANAJEMEN PROPOSAL SKRIPSI (STUDI KASUS JURUSAN MANAJEMEN INFORMATIKA POLITEKNIK NEGERI SAMBAS)
}

\author{
Sonty Lena', Renol Burjulius ${ }^{2}$ \\ 1,2Jurusan Manajemen Informatika, POLTESA; \\ Jl.Raya Sejangkung Kawasan Pendidikan Tinggi Sambas - Kalimantan Barat \\ e-mail: ${ }^{1}$ sontylena18@gmail.com, ${ }^{2}$ burjuliusrenol@gmail.com
}

\begin{abstract}
Abstrak
Mahasiswa tingkat akhir Jurusan Manajemen Informatika jenjang D3 Politeknik Negeri Sambas memiliki kewajiban untuk lulus seminar proposal skripsi sebagai syarat untuk dapat mengikuti pembimbingan skripsi. Namun dalam situasi pandemi Covid-19 saat ini terdapat kendala dalam kegiatan akademik mahasiswa, dimana terbatasnya kegiatan akademik yang bersifat tatap muka. Dikarenakan sangat pentingnya kegiatan akademik seperti proses seminar proposal yang harus tetap berjalan, maka dalam penelitian ini bertujuan untuk membuat sistem informasi pengajuan proposal agar dapat digunakan untuk kegiatan akademik mulai dari pengajuan proposal skripsi, verifikasi proposal skripsi, informaasi jadwal seminar serta monitoring kegiatan proposal skripsi. Adapun metodologi pengembangan perangkat lunak yang digunakan pada penelitian ini menggunakan metodologi prototyping, serta UML (Unified Modelling Language) sebagai metode permodelan secara visual untuk perancangan sistem berorientasi objek. Hasil dari penelitian ini adalah sistem informasi proposal skripsi berbasis web yang dapat diimplementasikan di jurusan Manajemen Informatika POLTESA sehingga dapat dijangkau seluruh civitas akademika dengan mudah pada periode tugas akhir serta dapat mempermudah pihak jurusan untuk mengolah pengajuan skripsi dan memonitoring mahasiswa yang sedang dalam tahap menempuh skripsi, dimana hasil penelitian ini sangat dibutuhkan disituasi pandemi Covid-19 saat ini.
\end{abstract}

Kata kunci- Proposal Skripsi, Covid-19, prototyping, UML (Unified Modeling Language)

\begin{abstract}
Final year students of the Department of Information Management at D3 State Polytechnic of Sambas have the obligation to pass the thesis proposal seminar as a condition of being able to participate in thesis guidance. However, in the current situation of the Covid19 pandemic there are obstacles in student academic activities, where face-to-face academic activities are limited. Due to the very importance of academic activities such as the proposal seminar process that must continue, this study aims to create a proposal submission information system so that it can be used for academic activities starting from submitting thesis proposals, verifying thesis proposals, informing seminar schedules and monitoring thesis proposal activities. The software development methodology used in this study uses the prototyping methodology, and UML (Unified Modeling Language) as a visual modeling
\end{abstract}


method for object-oriented system design. The result of this research is a web-based thesis proposal information system that can be implemented in the Department of Information Management POLTESA so that it can be easily reached by the entire academic community in the final project period and can make it easier for the department to process thesis submissions and monitor students who are in the thesis stage. where the results of this research are needed in the current situation of the Covid-19 pandemic.

Keywords - Thesis proposal, Covid-19, prototyping, UML (Unified Modeling Language)

\section{PENDAHULUAN}

Skripsi atau tugas akhir merupakan sebuah persyaratan bagi mahasiswa untuk mendapatkan gelar sarjana dan diploma disetiap Perguruan Tinggi, baik negeri maupun swasta. Beberapa proses skripsi atau tugas akhir antara lain pengajuan proposal skripsi, seminar proposal, bimbingan skripsi dan sidang skripsi.

Pada penelitian ini fokus pada pengajuan skripsi di Jurusan Manajemen informatika Politeknik Negeri Sambas, dimana terdapat 3 (tiga) program studi yaitu Manajemen Informatika (D3), Teknik Multimedia (D4), dan Akuntansi (D4). Adapun proses pengajuan proposal skripsi yang saat ini berlangsung di Jurusan Manajemen Informatika Politeknik Negeri Sambas, sebelum menempuh skripsi, mahasiswa terlebih dahulu berkewajiban mengikuti seminar proposal skripsi dimana sebelum dinyatakan berhak menempuh seminar proposal skripsi, mahasiswa terlebih dahulu wajib mengikuti beberapa tahapan yang dimulai dari mahasiswa mengajukan judul skripsi berbentuk proposal, selanjutnya proposal yang masuk akan di verifikasi dan ditentukan hasilnya, baik diterima, ditolak, maupun diterima dengan perbaikan oleh masing-masing program studi dan selanjutnya proposal yang layak akan dijadwalkan untuk mengikuti seminar proposal skripsi. Adapun Pihak-pihak yang terlibat dalam proses ini yaitu mahasiswa, dosen pembimbing, dosen penguji seminar, Staff Program Studi, Ketua Program Studi (Kaprodi), Ketua Jurusan (Kajur).

Adanya pandemi Covid-19 menjadi kendala dalam proses pengajuan proposal saat ini, dikarenakan mahasiswa harus datang ke kampus dan menyerahkan secara langsung proposal kepada staff program studi. Keadaan ini membuat Jurusan Manajemen Informatika Politeknik Negeri Sambas menghadirkan layanan pengajuan proposal secara online.

Berdasarkan hal tersebut penelitian ini akan dapat membantu pihak Jurusan dalam proses manajemen skripsi. Dengan adanya aplikasi web pengajuan judul skripsi menjadi lebih cepat dan mudah, karena proses pengajuan judul skripsi dapat dilakukan tanpa perlu adanya tatap muka antara satu pihak dengan pihak yang lain [1]. Adanya hasil penelitian ini maka pengajuan proposal skripsi dapat dilakukan darimana saja pada periode waktu pengajuan proposal skripsi. Dengan Pemanfaatan teknologi informasi diharapkan dapat mempermudah pihak jurusan untuk mengolah pengajuan skripsi dan memonitoring mahasiswa yang sedang dalam tahap menempuh skripsi yang sangat dibutuhkan disituasi pandemi Covid-19 saat ini. 


\section{METODOLOGI PENELITIAN}

\subsection{Tahapan Penelitian}

Dalam melakukan penelitian ini, terdapat beberapa tahapan yang dilakukan peneliti untuk mengembangkan sistem agar sesuai dengan rencana dan kebutuhan yang ada di Jurusan Manajemen Informatika Politeknik Negeri Sambas.

gambar 1 menunjukkan alur tahapan penelitian.

\begin{tabular}{|c|}
\hline Studi Literasi \\
\hline 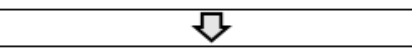 \\
\hline Analisa \\
\hline$\sqrt{3}$ \\
\hline Perancangan Sistem \\
\hline$\sqrt{3}$ \\
\hline Pembuatan Kode Program \\
\hline$\sqrt{3}$ \\
\hline Pengujian \\
\hline$\sqrt{2}$ \\
\hline Implementasi \\
\hline
\end{tabular}

\section{1.1 Studi Literatur}

Tahap pertama melakukan penelusuran terhadap penelitian-penelitian terdahulu dan beberapa sumber lainnya untuk dijadikan referensi pada penelitian saat ini. Penelitian yang sudah ada dapat dikembangkan agar lebih baik.

\section{1.2 Analisa}

Tahap selanjutnya adalah menganalisis masalah yang ada di Jurusan Manajemen Informatika POLTESA kemudian dijadikan peluang untuk mendukung dalam penentuan fitur yang dapat dikembangkan ke dalam sistem informasi proposal skripsi di Jurusan Manajemen Informatika POLTESA.

\section{1.3 Perancangan Sistem}

Sebelum menulis kode program, peneliti terlebih dahulu mendesain rancangan sistem agar pengerjaan sistem informasi manajemen proposal skripsi ini akan lebih mudah. Pada penelitian, perancangan menggunakan UML (Unified Modeling Language).

UML adalah salah satu standar bahasa yang banyak digunakan di dunia industri untuk mendefinisikan requirement, membuat analisis dan desain, serta menggambarkan arsitektur dalam pemrograman berorientasi objek [2].

Use case diagram merupakan diagram yang menggambarkan hubungan antara pengguna sistem (aktor) dengan sistem. Use case diagram bisa mendeskripsikan sebuah interaksi antara satu atau lebih aktor dengan sistem yang akan dibuat. Use case diagram juga bisa digunakan untuk mengetahui fungsionalitas di dalam sebuah sistem dan bisa juga mempresentasikan sebuah 
interaksi aktor dengan sistem. Terdapat dua elemen yang harus digambarkan pada sebuah use case diagram, yaitu aktor dan use case. Berikut ini deskripsi aktor yang ada pada sistem:

a. Admin; merupakan pihak Jurusan yang memiliki hak mengelola Jurusan, Program Studi, dan Pengguna (Staff Prodi, Dosen, Mahasiswa, Ketua Prodi, Ketua Jurusan ).

b. Staff Prodi; merupakan pihak yang dapat mengelola tema skripsi dan mengelola proposal skripsi dan menampilkan jumlah tema skripsi, total proposal skripsi, total proposal pending, total proposal diproses, total proposal disetujui, dan total proposal ditolak.

c. Dosen (Dosen Pembimbing/ Dosen Penguji); merupakan pihak yang dapat memonitoring mahasiswa yang dibimbing, unduh proposal dan informasi jadwal seminar mahasiswa yang akan diuji terkait dengan proposal skripsi.

d. Ketua Prodi; merupakan pihak yang dapat memonitoring mahasiswa yang ada diprodinya terkait dengan proposal skripsi apakah telah terkirim atau sedang diproses, disetujui atau ditolak.

e. Ketua Jurusan; merupakan pihak yang dapat memonitoring mahasiswa yang ada di Jurusannya terkait dengan proposal skripsi apakah sudah terkirim atau sedang diproses, disetujui atau ditolak.

f. Mahasiswa; merupakan pihak yang dapat mengajukan proposal skripsi dan menampilkan jadwal seminar proposal skripsi.

Berikut use case sistem pada penelitian:

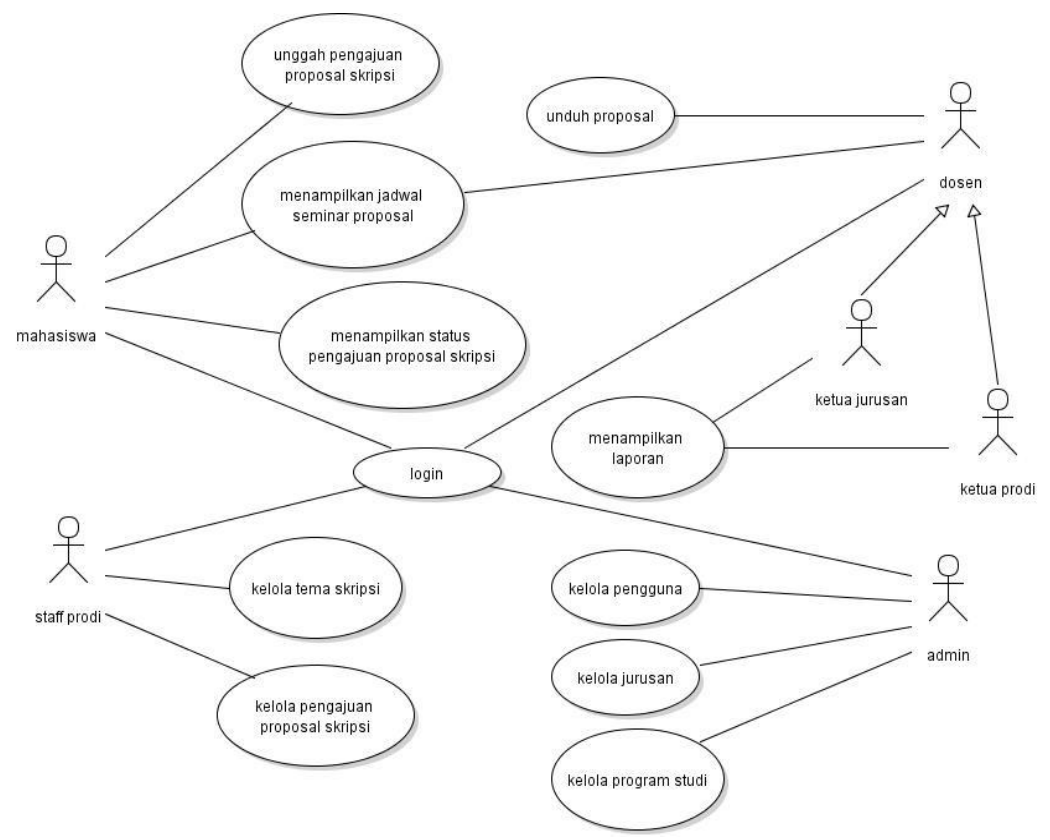

Gambar 2. Use case Sistem 


\section{1.4 Pembuatan Kode Program}

Pada tahapan ini adalah pembuatan kode program yang digunakan dalam mentranslasikan tahapan perancangan sistem. Pada penlitian ini menggunakan bahasa pemrograman PHP dan untuk pembuatan database menggunakan MySQL.

PHP (Hypertext Preprocessor) adalah bahasa script yang dapat ditanamkan atau disisipkan ke dalam HTML [3]. PHP banyak dipakai untuk membuat program situs web dinamis". PHP bersifat Open Source. Dan MySQL adalah database server open source yang cukup popular keberadaannya. Dengan berbagai keunggulan yang dimiliki, membuat software database ini banyak digunakan oleh praktisi untuk membangun suatu project [4]. Adanya fasilitas API (Application Programming Interface) yang dimiliki oleh MySQL, memungkinkan bermacammacam aplikasi komputer yang ditulis dengan berbagai bahasa pemrograman dapat mengakses basis data MySQL.

\section{1.5. Pengujian}

Setelah sistem dibangun, tahap selanjutnya adalah menguji dan memastikan sistem memiliki kinerja dan fungsi yang sesuai dengan tujuan penelitian untuk meminimalisir kesalahan (error) dan memastikan keluaran yang dihasilkan sesuai dengan yang diinginkan, penelitian ini menggunakan metode black-box testing. Blackbox testing merupakan pengujian yang berorientasi pada fungsionalitas yaitu perilaku dari perangkat lunak atas input yang diberikan pengguna sehingga mendapatkan/ menghasilkan output yang diinginkan tanpa melihat proses internal atau kode program yang dieksekusi oleh perangkat lunak [5].

\section{1.6 Implementasi}

Setelah sistem melewati tahap pengujian, sistem di jalankan pada server berbasis IP Publik yang didalamnya telah tersedia web server dan database server sehingga siap digunakan sebagaimana tujuan penelitian ini ditulis. Web server adalah "Server Web (Web Server) merujuk pada perangkat keras (server) dan perangkat lunak yang menyediakan layanan akses kepada pengguna melalui protokol komunikasi HTTP ataupun variannya (seperti FTP dan HTTPS) atas berkas-berkas yang terdapat pada suatu URL ke pemakai" [6].

Database server adalah sebuah program komputer yang menyediakan layanan pengelolaan basis data dan melayani komputer atau program aplikasi basis data yang menggunakan model client-server. Istilah ini juga merujuk kepada sebuah komputer (umumnya merupakan server) yang didedikasikan untuk menjalankan program yang bersangkutan. Sistem manajemen basis data (DBMS) pada umumnya menyediakan fungsi-fungsi server basis data, dan beberapa DBMS (seperti halnya MySQL atau Microsoft SQL Server) sangat bergantung kepada model clientserver untuk mengakses basis datanya [7]. 


\section{HASIL DAN PEMBAHASAN}

\section{1 Hasil Website}

\subsubsection{Halaman Beranda}

Halaman beranda dapat diakses oleh semua tingkatan pengguna untuk menginputkan username berupa NIP/NIDN/NIM dan password. Gambar 3 menampilkan halaman beranda.

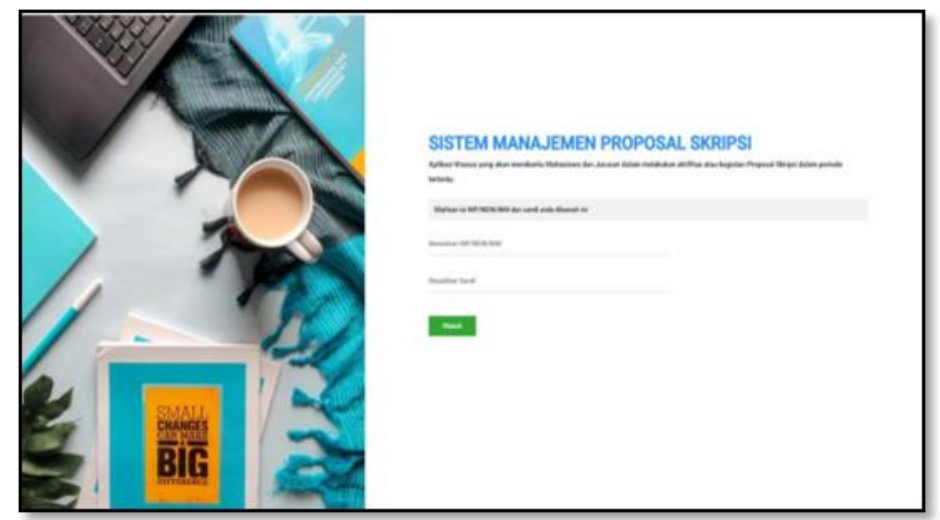

Gambar 3. Halaman Beranda

\subsubsection{Halaman Admin}

Pada halaman admin (home) menampilkan 6 data : total jurusan, total program studi, total kepala jurusan, total kepala prodi, total dosen, dan total mahasiswa. dan terdapat 3 menu untuk mengelola jurusan, program studi, dan pengguna (staff prodi, dosen, mahasiswa). Gambar 4 menampilkan halaman admin.

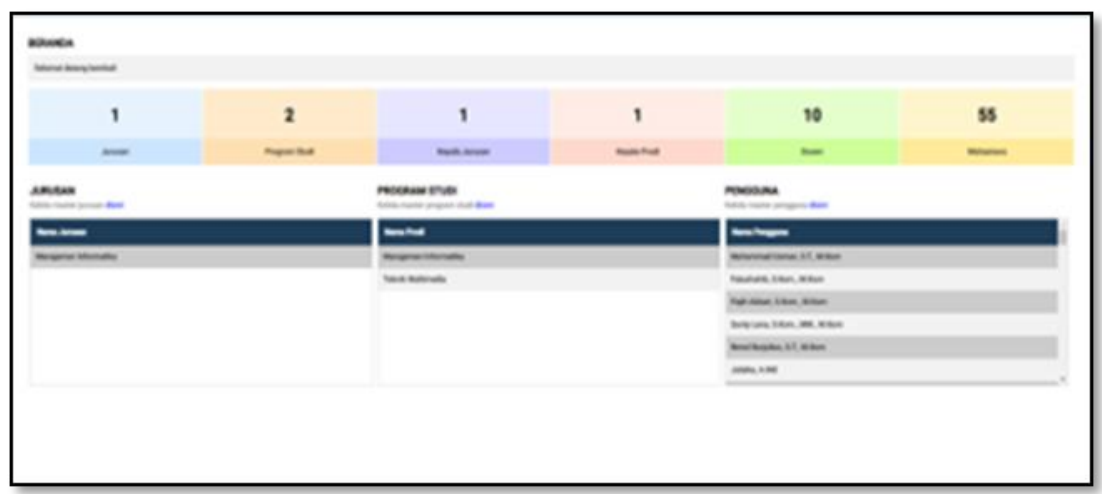

Gambar 4. Halaman Admin

\subsubsection{Halaman Mahasiswa}

Pada halaman mahasiswa menampilkan 6 data : total tema skripsi, total proposal skripsi, total proposal terkirim, total proposal diproses, total proposal disetujui, dan total proposal ditolak. Dan terdapat 2 Menu untuk menampilkan jadwal sidang proposal skripsi dan menu untuk mengajukan proposal skripsi. Gambar 5 menampilkan halaman mahasiswa. 


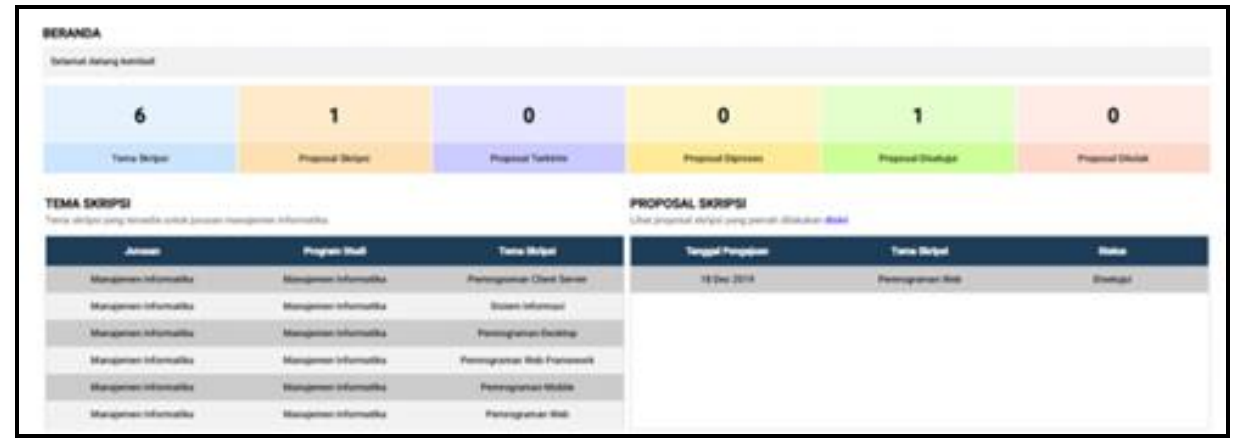

Gambar 5. Halaman Mahasiswa

\subsubsection{Halaman Staff Prodi}

Pada halaman Staff Prodi menampilkan 6 data : total tema skripsi, total proposal skripsi, total proposal pending, total proposal diproses, total proposal disetujui, dan total proposal ditolak. dan terdapat 2 menu untuk kelola tema skripsi dan kelola proposal skripsi. Gambar 6 menampilkan halaman Staff Prodi.

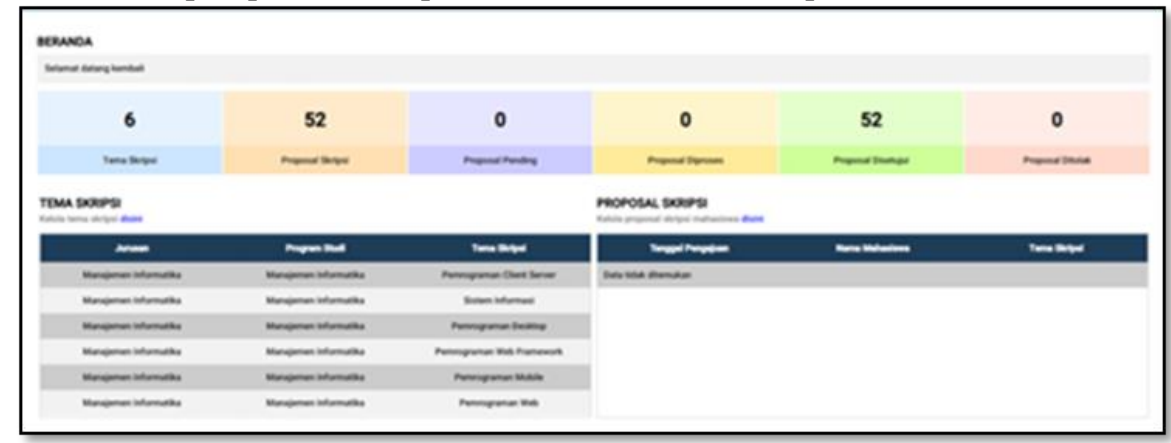

Gambar 6. Halaman Staff Prodi

\subsubsection{Halaman Dosen (Dosen Pembimbing/ Dosen Penguji)}

Pada halaman dosen digunakan dosen untuk memonitoring mahasiswa yang dibimbing dan mahasiswa yang akan diuji terkait dengan proposal skripsi. Terdapat 2 (dua) menu yaitu.

a. Menu Daftar Mahasiswa Bimbingan

Dosen dapat sebagai Pembimbing, sehingga dosen dapat memonitoring mahasiswa yang dibimbing, apakah telah Disetujui atau Ditolak.

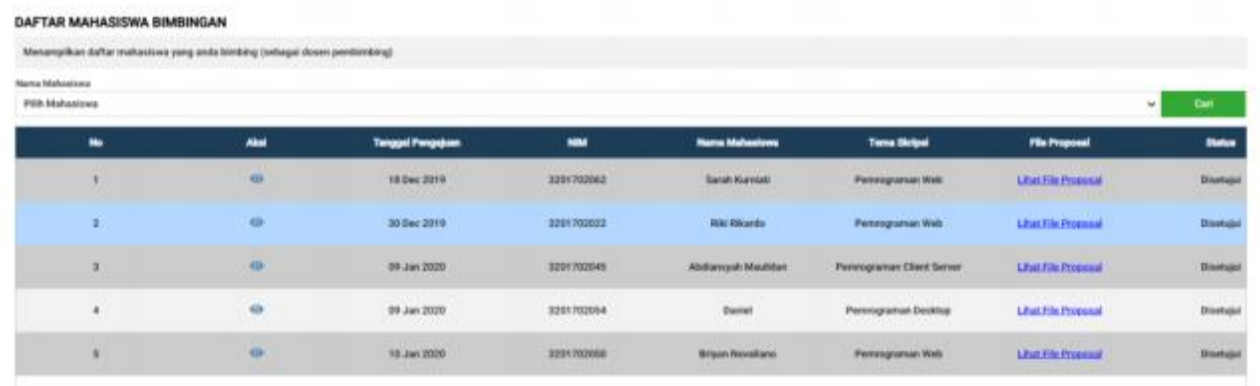

Gambar 7. Halaman Daftar Mahasiswa Bimbingan 
b. Menu Daftar Sidang Mahasiswa

Dosen dapat sebagai penguji, sehingga dosen dapat melihat daftar sidang mahasiswa yang diuji.

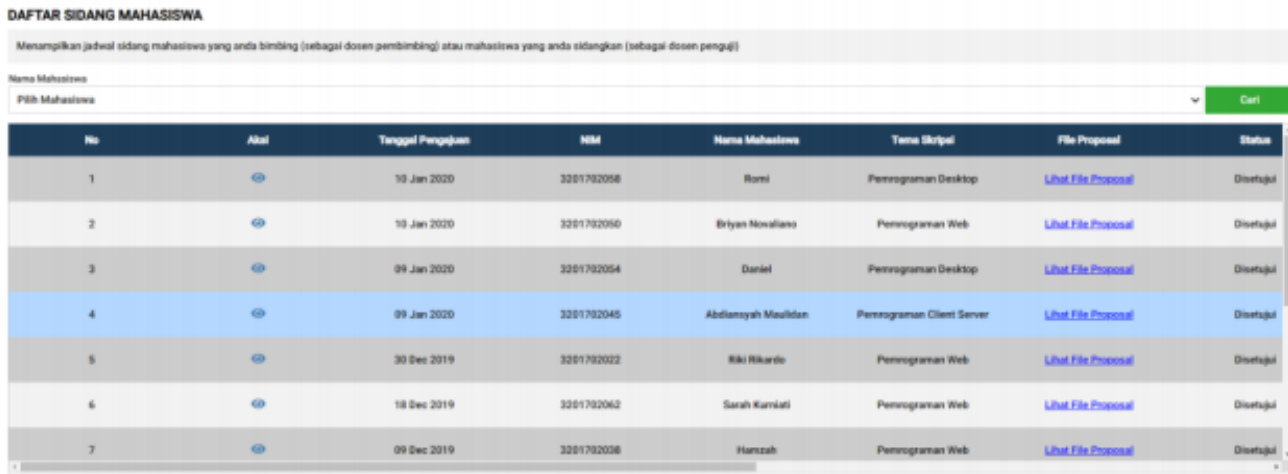

Gambar 8. Halaman Daftar Sidang Mahasiswa

\subsubsection{Halaman Ketua Prodi}

Terdapat 3 (tiga) menu sebagai pengguna Ketua Prodi. Pada halaman ini, Ketua Prodi dapat memonitoring mahasiswa yang ada diprodinya terkait dengan proposal skripsi apakah telah terkirim atau sedang Diproses, Disetujui atau Ditolak.

a. Menu Daftar Mahasiswa Prodi

Di menu ini Ketua Prodi dapat melihat Status Proposal Mahasiswa yang ada di Prodi nya. Berdasarkan Filter yang diinginkan. Dan dapat Ekspor ke dalam File Excel dan file PDF.

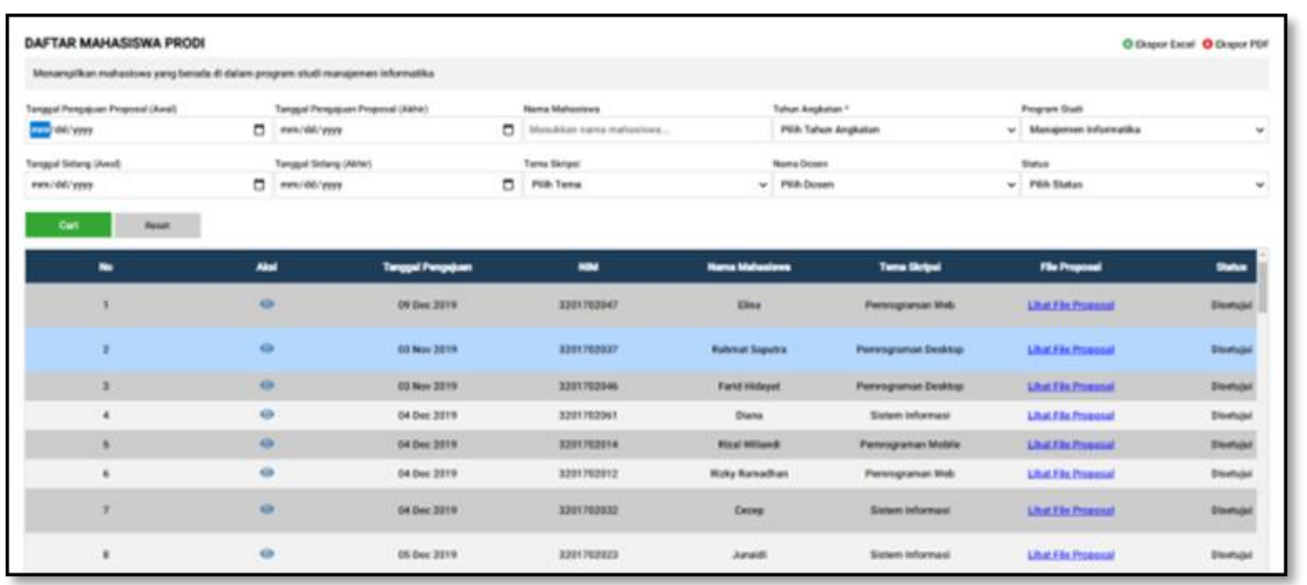

Gambar 9. Daftar Mahasiswa Prodi

b. Menu Daftar Mahasiswa Bimbingan

Di menu ini Ketua Prodi dapat sebagai Pembimbing, sehingga Ketua Prodi dapat memonitoring mahasiswa yang dibimbingnya apakah sudah Disetujui atau Ditolak 


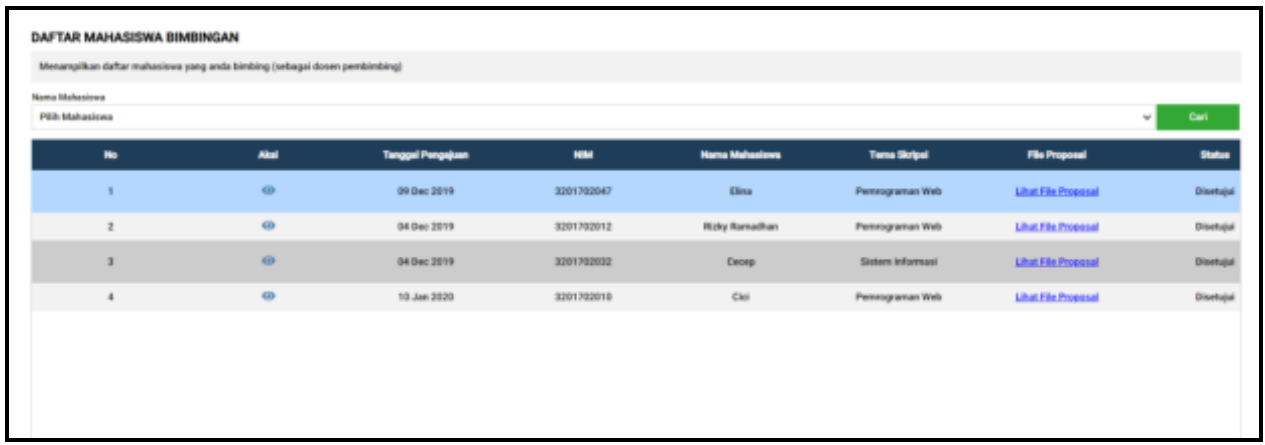

Gambar 10. Daftar Mahasiswa Bimbingan

c. Menu Daftar Sidang Mahasiswa

Di menu ini Ketua Prodi dapat sebagai Penguji, sehingga Ketua Prodi dapat melihat daftar sidang mahasiswa di Prodinya dan mahasiswa yang diuji.

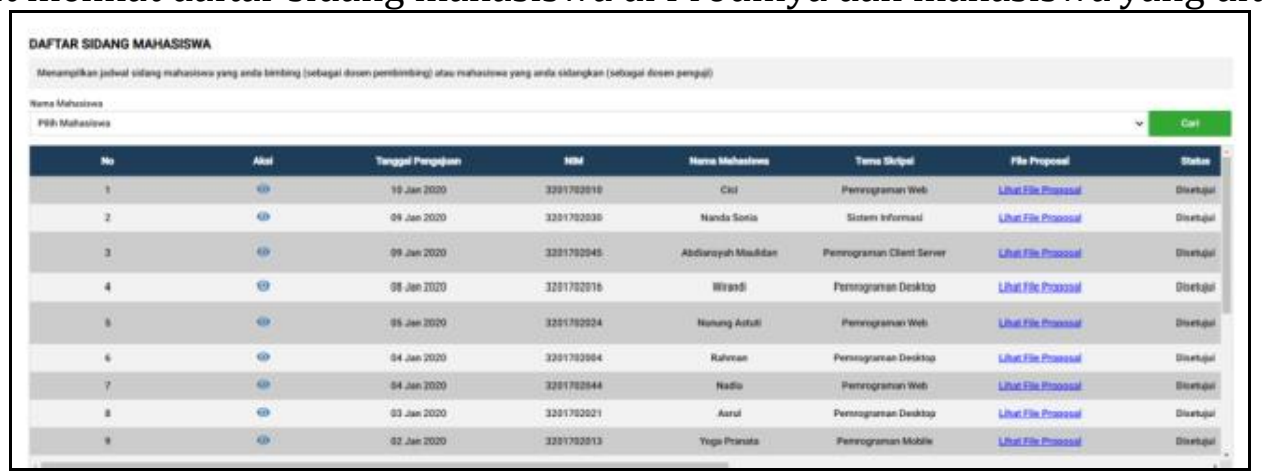

Gambar 11. Daftar Sidang Mahasiswa

\subsubsection{Halaman Ketua Jurusan}

Dimana menu ini digunakan Ketua Jurusan untuk memonitoring mahasiswa yang ada Di Jurusannya terkait dengan Proposal TA apakah Sudah terkirim atau sedang Diproses, Disetujui atau Ditolak. Terdapat 3 (tiga) menu sebagai Pengguna Ketua Jurusan.

a. Menu Daftar Mahasiswa Jurusan

Di menu ini Ketua Jurusan dapat melihat Status Proposal Mahasiswa yang ada di Jurusanya. Berdasarkan Filter yang diinginkan. Dan dapat Ekspor ke dalam File Excel dan file PDF. 


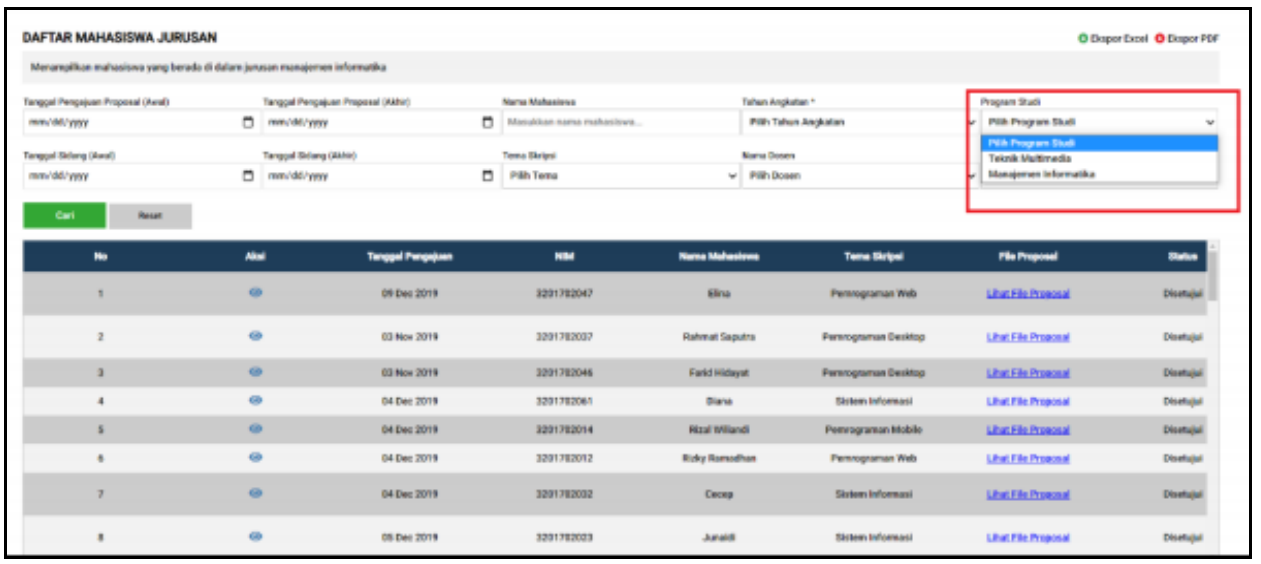

Gambar 12. Daftar Mahasiswa Jurusan

b. Menu Daftar Mahasiswa Bimbingan

Di menu ini Ketua Jurusan dapat sebagai Pembimbing, sehingga Ketua Jurusan dapat memonitoring mahasiswa yang dibimbingnya apakah sudah Disetujui atau Ditolak.

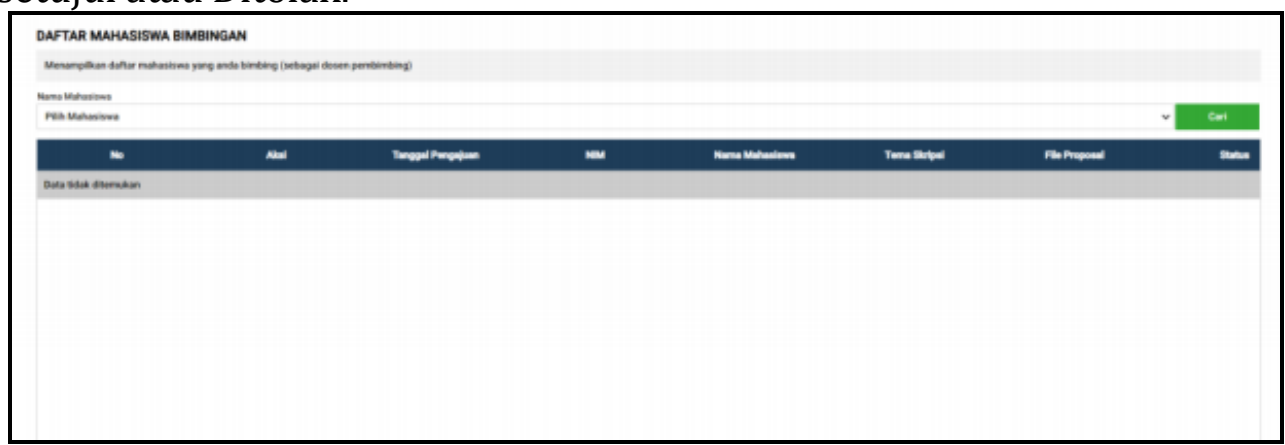

Gambar 13. Daftar Mahasiswa Bimbingan

c. Menu Daftar Sidang Mahasiswa

Di menu ini Ketua Jurusan dapat sebagai Penguji, sehingga Ketua Jurusan dapat melihat daftar sidang mahasiswa di Jurusan.

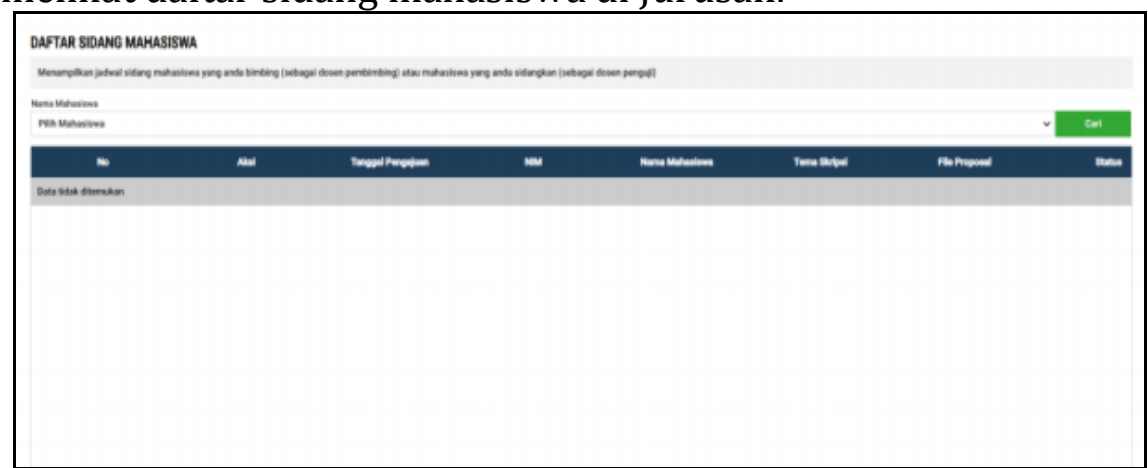

Gambar 14. Daftar Sidang Mahasiswa 


\section{SIMPULAN}

Dari hasil penelitian ini dapat disimpulkan bahwa sistem informasi yang dirancang menggunakan model pengembangan sistem Prototyping dan UML (Unified Modeling Language) dan dikembangkan dalam platform berbasis web dapat diimplementasikan di jurusan Manajemen Informatika Politeknik Negeri Sambas. Layanan yang dapat diakses berupa pengajuan skripsi oleh mahasiswa, verifikasi proposal, informaasi jadwal seminar serta monitoring pelaksanan proposal skripsi. Sehingga proses pengajuan proposal menjadi lebih efektif dan efisien karena dapat dijangkau seluruh civitas akademika dengan mudah pada periode tugas akhir dimana saja dan darimana saja, serta pihak Jurusan dapat dengan mudah dalam memonitoring mahasiswa yang sedang menempuh skripsi. Adapun saran untuk penelitian lebih lanjut dapat dikembangkan dengan adanya layanan bimbingan skripsi secara online.

\section{DAFTAR PUSTAKA}

[1] T. Widaretna, M. Naseer, and I. Supriadi, "Pengembangan Aplikasi Web Pengajuan Judul Skripsi Dengan Framework Codeigniter Dan HTML 5 Pada Sekolah Tinggi," Seminar Nasional. Informatika. dan Sistem Informasi., pp. 200221, 2017.

[2] M. A. S., Rosa dan Shalahuddin, Rekayasa Perangkat Lunak Terstruktur Dan Berorientasi Objek. Bandung: Informatika Bandung, 2014.

[3] Madcom, Pemrograman PHP dan MySQL Untuk Pemula. Yogyakarta: Andi, 2016.

[4] W. Komputer, Panduan Belajar MySql Database Server. Jakarta Selatan: Media Kita, 2010.

[5] D. Febiharsa, I. M. Sudana, and N. Hudallah, "Uji Fungsionalitas (BlackBox Testing) Sistem Informasi Lembaga Sertifikasi Profesi (SILSP) Batik Dengan AppPerfect Web Test Dan Uji Pengguna," JOINED J., vol. 1, no. 2, pp. 117-126, 2018, [Online]. Available: http://ejournal.ivet.ac.id/index.php/jiptika/article/view/752.

[6] Fathansyah, Basis Data. Bandung: Informatika Bandung, 2012.

[7] A. Haryawan, "Perbandingan Kinerja Database Server Mysql Dan Sql Server ( Studi Kasus Database Server Politama Surakarta )," vol. XV, no. 1, pp. 43-49, 2016. 